\title{
Lattice mismatch and crystallographic tilt induced by high-dose ion-implantation into $4 \mathrm{H}-\mathrm{SiC}$
}

\section{$\operatorname{AUTHOR}(\mathrm{S}):$}

Sasaki, S.; Suda, J.; Kimoto, T.

\section{CITATION:}

Sasaki, S. ... [et al]. Lattice mismatch and crystallographic tilt induced by high-dose ionimplantation into 4H-SiC. Journal of Applied Physics 2012, 111(10): 103715.

\section{ISSUE DATE:}

2012-05-25

URL:

http://hdl.handle.net/2433/187960

\section{RIGHT:}

(c) 2012 American Institute of Physics. This article may be downloaded for personal use only. Any other use requires prior permission of the author and the American Institute of Physics. 


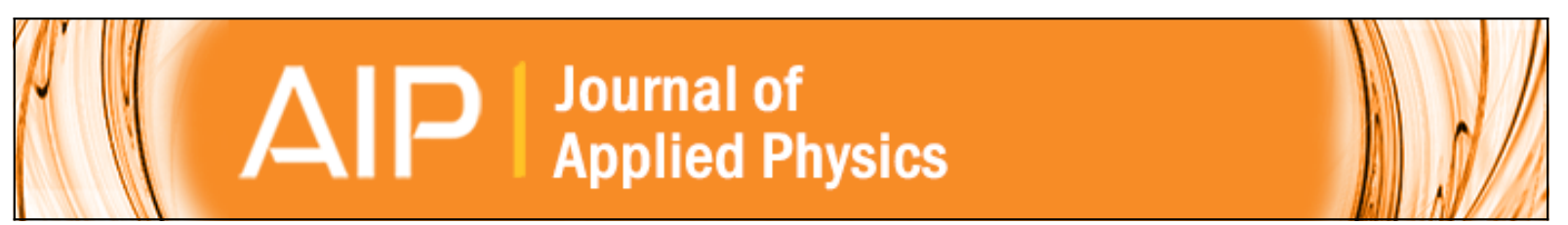

Lattice mismatch and crystallographic tilt induced by high-dose ion-implantation into 4H-SiC

S. Sasaki, J. Suda, and T. Kimoto

Citation: Journal of Applied Physics 111, 103715 (2012); doi: 10.1063/1.4720435

View online: http://dx.doi.org/10.1063/1.4720435

View Table of Contents: http://scitation.aip.org/content/aip/journal/jap/111/10?ver=pdfcov

Published by the AIP Publishing

\section{Articles you may be interested in}

Enhanced annealing of implantation-induced defects in $4 \mathrm{H}-\mathrm{SiC}$ by thermal oxidation

Appl. Phys. Lett. 98, 052108 (2011); 10.1063/1.3531755

Annealing induced extended defects in as-grown and ion-implanted $4 \mathrm{H}-\mathrm{SiC}$ epitaxial layers

J. Appl. Phys. 108, 013511 (2010); 10.1063/1.3457840

Effects of high-temperature anneals on $4 \mathrm{H}-\mathrm{SiC}$ Implanted with $\mathrm{Al}$ or $\mathrm{Al}$ and $\mathrm{Si}$

J. Appl. Phys. 96, 5613 (2004); 10.1063/1.1798404

High-energy (MeV) Al and B ion implantations into $4 \mathrm{H}-\mathrm{SiC}$ and fabrication of pin diodes

J. Appl. Phys. 91, 4242 (2002); 10.1063/1.1459096

Comparison of the annealing behavior of high-dose nitrogen-, aluminum-, and boron-implanted $4 \mathrm{H}-\mathrm{SiC}$ Appl. Phys. Lett. 72, 2026 (1998); 10.1063/1.121681

\section{AlP Re-register for Table of Content Alerts}




\title{
Lattice mismatch and crystallographic tilt induced by high-dose ion-implantation into $\mathbf{4 H}-\mathrm{SiC}$
}

\author{
S. Sasaki, ${ }^{\text {a) }}$ J. Suda, and T. Kimoto \\ Department of Electronic Science and Engineering, Kyoto University, Katsura, Nishikyo, \\ Kyoto 615-8510, Japan
}

(Received 1 December 2011; accepted 20 April 2012; published online 25 May 2012)

\begin{abstract}
Lattice parameters of high-dose ion-implanted $4 \mathrm{H}-\mathrm{SiC}$ were investigated with reciprocal space mapping $(\mathrm{RSM})$. $\mathrm{N}, \mathrm{P}, \mathrm{Al}$, or $(\mathrm{C}+\mathrm{Si})$ ions were implanted into lightly doped epilayers to form a (330-520) nm-deep box profile with concentrations of $10^{19}-10^{20}$ atoms $/ \mathrm{cm}^{3}$. After activation annealing at $1800^{\circ} \mathrm{C}$, RSM measurements were conducted. The RSM images for (0008) reflection revealed that high-dose ion implantation causes $c$-lattice expansion in implanted layers, irrespective of ion species. In addition, crystallographic tilt was observed after high-dose ion implantation. The tilt direction is the same for all the samples investigated; the $c$-axis of the implanted layers is inclined toward the ascending direction of the off-cut. The $c$-lattice mismatch and the tilt angle increased as the implantation dose increases, indicating that the implantation damage is responsible for the lattice parameter change. From these results and transmission electron microscopy observation, the authors conclude that the $c$-lattice mismatch and the crystallographic tilt are mainly caused by secondary defects formed after the ion-implantation and activation-annealing process. (c) 2012 American Institute of Physics. [http://dx.doi.org/10.1063/1.4720435]
\end{abstract}

\section{INTRODUCTION}

Silicon carbide $(\mathrm{SiC})$ is a promising wide bandgap semiconductor for high-temperature, high-voltage, and highfrequency devices. ${ }^{1,2}$ Among many $\mathrm{SiC}$ polytypes, $4 \mathrm{H}-\mathrm{SiC}$ is regarded as the most suitable polytype owing to its large bandgap, high electron mobility, and small anisotropy. In the past decades, both the crystal quality and the device fabrication technology have been greatly improved, and $\mathrm{SiC}$ Schottky barrier diodes (SBDs) and metal-oxide-semiconductor field-effect transistors (MOSFETs) are now on the market from several manufacturers. However, various kinds of defects still remain in $\mathrm{SiC}$ crystals, which can adversely affect the device performance and reliability. For further reduction or precise control of defect density, deep understanding of various defects in $\mathrm{SiC}$ is required.

Selective area doping is necessary for fabricating most electronic devices to achieve the optimum device operation. Ion implantation is usually employed for $\mathrm{SiC}$ device fabrication, since the diffusion constants of dopant atoms are extremely low. Although fundamental technology of ion implantation has been developed in the past decades, ${ }^{3,4}$ ion implantation can leave serious damage in the lattice sites; generation of point defects ${ }^{5,6}$ and structural defects, ${ }^{7-9}$ polytype transition, surface swelling, ${ }^{10}$ and amorphization. Excess interstitial atoms generated by ion implantation can migrate during post-implantation annealing, resulting in the formation of clusters and platelet defects. ${ }^{7-9,11-13}$ Surface swelling was found to be proportional to the area density of displaced atoms in addition to the amorphous transition. ${ }^{10}$ These implantation-induced defects can remain in the crystal even after high-temperature annealing, and affect the carrier transport. ${ }^{14,15}$ High-dose ion implantation $\left(>10^{15} \mathrm{~cm}^{-2}\right)$ is

${ }^{a)}$ Electronic mail: sasaki@semicon.kuee.kyoto-u.ac.jp. required to achieve lower contact resistance at the region where metal contacts are formed. In the $\mathrm{SiC}$ device fabrication, phosphorous implantation is effective for the formation of $\mathrm{n}^{+}$region with a low sheet resistance, ${ }^{16,17}$ and aluminum implantation for the formation of $\mathrm{p}^{+}$region. ${ }^{4,18}$ To create such heavily doped regions, ions with a concentration of more than $10^{19}$ atoms $/ \mathrm{cm}^{3}$ are usually implanted into $\mathrm{SiC}$ crystals. Such high concentration of impurity atoms may affect the SiC lattice constants. In this study, the authors focus on lattice mismatch and crystallographic tilt in highdose ion-implanted $4 \mathrm{H}-\mathrm{SiC}$.

Several groups have investigated doping-induced lattice mismatch in SiC layers. ${ }^{19-23}$ Their results suggest that the lattice contraction is caused by heavy nitrogen doping and lattice expansion by heavy aluminum doping, due to the atomic size difference. Doping-induced lattice mismatch has also been indicated by the formation of interfacial dislocations (IDs). ${ }^{24-26}$ IDs have been observed at the epilayer/substrate interface and at the bottom of the ion-implanted region. IDs can be formed by the glide of basal plane dislocations (BPDs) due to thermal stress and misfit stress during the high-temperature process (growth or annealing). ${ }^{24-26}$ BPDs, including IDs, degrade the bipolar devices, since they act as nucleation sites of stacking-fault generation upon carrier injection. ${ }^{27,28}$ In this work, the authors attempt to clarify the influence of heavy doping on lattice parameters of $4 \mathrm{H}-\mathrm{SiC}$ crystals doped by ion implantation.

\section{EXPERIMENTS}

The starting materials were lightly doped p-type $4 \mathrm{H}-\mathrm{SiC}$ epilayers grown on heavily-doped $8^{\circ}$ off-axis $4 \mathrm{H}-\mathrm{SiC}(0001)$ substrates. The epilayer thickness and doping concentration were $50 \mu \mathrm{m}$ and $9.6 \times 10^{14} \mathrm{~cm}^{-3}$, respectively. $\mathrm{N}, \mathrm{P}$, or $\mathrm{Al}$ ions were implanted at $600^{\circ} \mathrm{C}$ from the sample surface to a 
TABLE I. Implantation conditions used for forming box profiles of nitrogen, phosphorus, and aluminum with a mean concentration of $5 \times 10^{19}$ atoms $/ \mathrm{cm}^{3}$.

\begin{tabular}{lccc}
\hline \hline & Nitrogen & Phosphorus & Aluminum \\
\hline $\begin{array}{c}\text { Acceleration } \\
\text { energy } \\
(\mathrm{keV})\end{array}$ & $350,240,160,100$, & $350,240,180,100$, & $350,220,130,70$, \\
Total dose & $55,25,10$ & $50,24,10$ & 35,15 \\
$\left(\mathrm{~cm}^{-2}\right)$ & $2.75 \times 10^{15}$ & $1.78 \times 10^{15}$ & $2.47 \times 10^{15}$ \\
Depth $(\mu \mathrm{m})$ & 0.52 & 0.33 & 0.45 \\
\hline \hline
\end{tabular}

depth of $330-520 \mathrm{~nm}$ with a box profile of $1 \times 10^{19}-1$ $\times 10^{20}$ atoms $/ \mathrm{cm}^{3}$. For one sample, $\mathrm{C}$ and $\mathrm{Si}$ ions were successively implanted with a mean concentration of $5 \times 10^{19}$ atoms $/ \mathrm{cm}^{3}$. In the case of $\left(\mathrm{C}^{+}+\mathrm{Si}^{+}\right)$co-implantation, a half dose for each ion species $\left(\mathrm{C}^{+}\right.$or $\left.\mathrm{Si}^{+}\right)$was required to generate a box profile of $5 \times 10^{19}$ atoms $/ \mathrm{cm}^{3}$. All the samples were implanted at normal incidence with respect to the surface (the ion beam was $8^{\circ}$ tilted from the $c$-axis). Acceleration energy, total dose, and implanted depth used to form a box profile with a concentration of $5 \times 10^{19}$ atoms $/ \mathrm{cm}^{3}$ are shown in Tables I and II. The depth profiles of implanted atoms were obtained by SRIM simulation ${ }^{29,30}$ using threshold displacement energy of $22 \mathrm{eV}$ for both $\mathrm{C}$ and $\mathrm{Si}$ sublattices. ${ }^{31}$ The depth profiles obtained by SRIM simulation are shown in Figure 1. After the ion-implantation, activation annealing was performed in $\mathrm{Ar}$ ambient at $1800^{\circ} \mathrm{C}$ for $10 \mathrm{~min}$. Carbon caps ${ }^{17}$ were employed during the high-temperature annealing to protect the sample surface. After removing the carbon caps, lattice parameters were measured with reciprocal space mapping (RSM) using (0008) reflection. From the RSM images for (0008) reflection, vertical lattice mismatch and misorientation can be simultaneously evaluated. The $\mathrm{Cu} K \alpha_{1}$ line $(\lambda=1.540562 \AA)$ was used for the $\mathrm{x}$-ray measurements. The penetration length in $\mathrm{SiC}$ is about $70 \mu \mathrm{m}$ for the $\mathrm{Cu} K \alpha_{1}$ line, and the incident $\mathrm{x}$-ray used for the (0008) reflection is inclined by about $29.6^{\circ}$ from the sample surface. Therefore, reflection signals in the (0008) RSM measurements were collected mainly from ion-implanted layers and lightly doped epilayers. To observe structural defects generated by the ion implantation and annealing process, transmission electron microscopy (TEM) images were taken on ion-implanted and annealed samples. The TEM specimens were prepared using a focused $\mathrm{Ga}$ ion beam (FIB) technique. The thickness of the specimens was about $0.2 \mu \mathrm{m}$, and the TEM observation was operated at an energy of $300 \mathrm{keV}$.

TABLE II. Implantation conditions used for forming a box profile of carbon and silicon with a mean concentration of $5 \times 10^{19}$ atoms $/ \mathrm{cm}^{3}$.

\begin{tabular}{lcc}
\hline \hline & Carbon & Silicon \\
\hline Acceleration energy & $180,120,80$, & $350,230,140$, \\
$\quad(\mathrm{keV})$ & $50,25,10$ & $80,40,18$ \\
Total dose $\left(\mathrm{cm}^{-2}\right)$ & $9.37 \times 10^{14}$ & $9.37 \times 10^{14}$ \\
Depth $(\mu \mathrm{m})$ & 0.34 & 0.34 \\
\hline \hline
\end{tabular}

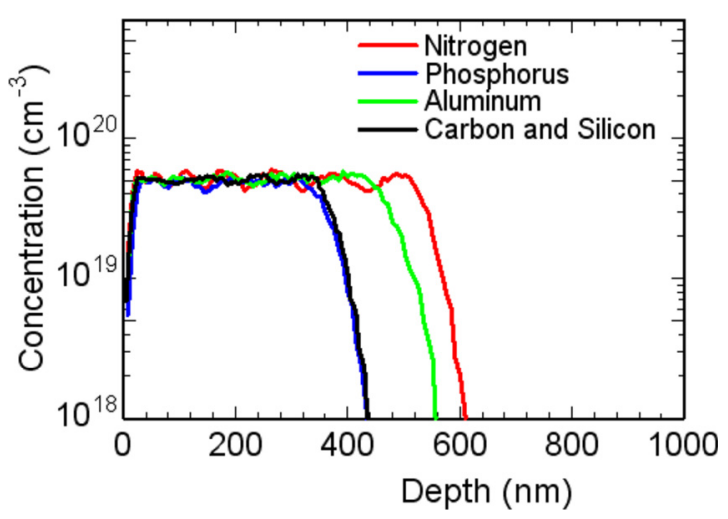

FIG. 1. Depth profiles of implanted atoms with a mean concentration of $5 \times$ $10^{19}$ atoms $/ \mathrm{cm}^{3}$ obtained by SRIM simulation.

\section{RESULTS AND DISCUSSION}

\section{A. RSM measurements on ion-implanted $4 \mathrm{H}-\mathrm{SiC}$}

Fig. 2 shows the RSM images for (0008) reflection of the $\mathrm{P}^{+}$-implanted $4 \mathrm{H}-\mathrm{SiC}$ with a phosphorus concentration of (a) $1 \times 10^{19}$, (b) $5 \times 10^{19}$, and (c) $1 \times 10^{20}$ atoms $/ \mathrm{cm}^{3}$. These implanted samples were annealed before the $\mathrm{x}$-ray measurements. The sample, which was $\mathrm{P}^{+}$-implanted with $1 \times 10^{19}$ atoms $/ \mathrm{cm}^{3}$, does not exhibit clear peak splitting in the RSM image (Fig. 2(a)). On the other hand, Figs. 2(b) and 2(c) reveal two distinct reflection peaks, originating from the implanted layer and the epilayer, respectively. The ratio of the reflection intensity from each peak is about $3 \%$, which approximately coincides with the value expected from the penetration depth of the incident x-ray. The RSM images of a not-implanted (as-grown) sample show single reflection peak, which corresponds to each reflection peak labeled as "epilayer" in Fig. 2. Therefore, the authors assigned two reflection peaks as indicated in the figures. The RSM images in Fig. 2 show the increase in the $c$-lattice constant (decrease in $\mathrm{q}_{\mathrm{z}}$ : [0001]) of the ion-implanted layers compared with that

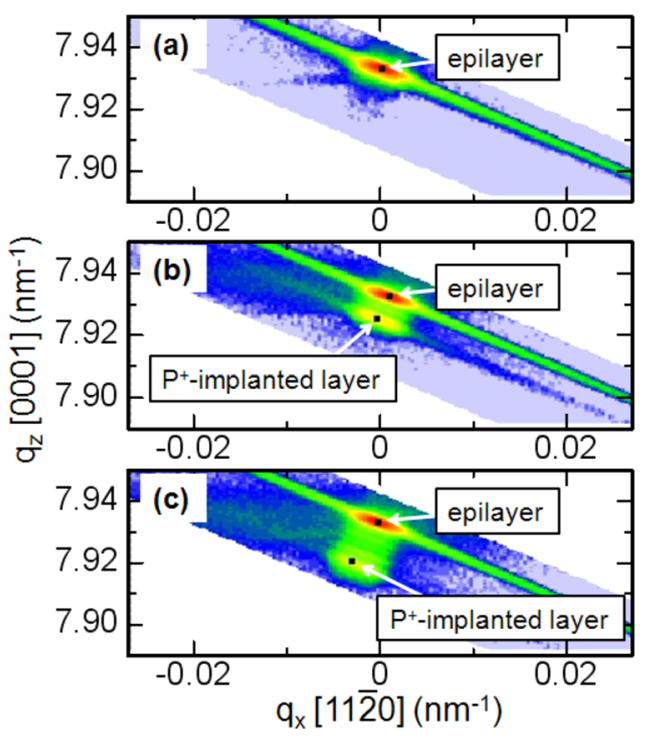

FIG. 2. (0008) RSM images of $4 \mathrm{H}-\mathrm{SiC}, \mathrm{P}^{+}$-implanted with (a) $1 \times 10^{19}$, (b) $5 \times 10^{19}$, and (c) $1 \times 10^{20}$ atoms $/ \mathrm{cm}^{3}$. The samples were annealed at $1800^{\circ} \mathrm{C}$ for $10 \mathrm{~min}$. 
of the epilayers. In these RSM images, minor reflection signals between the main peaks are observed, indicating intermediate region in the implanted layers. Since the solubility of $\mathrm{P}$ atoms in $\mathrm{SiC}$ is higher than the concentrations used in this study, most of the implanted $\mathrm{P}$ atoms should be electrically activated by post-implantation annealing. ${ }^{18,32}$ Negoro et al. ${ }^{18}$ and Laube et al. ${ }^{32}$ have demonstrated that more than $50 \%$ of implanted $\mathrm{P}$ atoms act as ionized donors at RT in 4H-SiC using similar implantation dose and annealing conditions. Substitutional $\mathrm{P}$ atoms should not cause the lattice expansion in $4 \mathrm{H}-\mathrm{SiC}$ crystals, since $\mathrm{P}$ atoms have a smaller covalent radius than $\mathrm{Si}$ atoms. Therefore, the $c$-lattice expansion observed in the $\mathrm{P}^{+}$-implanted layers cannot be explained by the atomic size difference. In addition to the lattice expansion, Figs. 2(b) and 2(c) also show that the two reflection peaks are located at the slightly different $\mathrm{q}_{\mathrm{x}}$ values $\left(\mathrm{q}_{\mathrm{x}}:[11 \overline{2} 0]\right)$, meaning that the basal planes of the $\mathrm{P}^{+}$implanted layers are tilting with respect to the basal planes of the epilayers. The observed tilt direction is schematically shown in Fig. 3. The tilt angle is overscaled in the illustration. In this figure, the incident $\mathrm{x}$-ray direction used for the RSM measurements in Fig. 2 is also indicated. The relative peak positions in the RSM images were reversed when the direction of the incident $\mathrm{x}$-ray was rotated by $180^{\circ}$, i.e., the peak from the implanted layer is located at larger $q_{x}$ values than the epilayer peak. When $\mathrm{P}$ ions were implanted with $5 \times 10^{19}$ atoms $/ \mathrm{cm}^{3}$, the $c$-lattice mismatch between the implanted layer and the epilayer can be estimated as about $9.5 \times 10^{-4}$, and the tilt angle as about $0.012^{\circ}$. These values increased as the implantation dose increases. More detailed evaluation is described in Sec. III B.

Figs. 4(a) and 4(b) depict the RSM images for (0008) reflection of the $\mathrm{Al}^{+}$-implanted ((a) $1 \times 10^{19}$ and (b) $5 \times 10^{19}$ atoms $/ \mathrm{cm}^{3}$ ) and annealed $4 \mathrm{H}-\mathrm{SiC}$. The $c$-lattice expansion and $c$-axis tilt were also observed in the high-dose $\mathrm{Al}^{+}$-implanted sample (Fig. 4(b)). The tilt direction observed in the $\mathrm{Al}^{+}$-implanted sample is the same as that observed in the $\mathrm{P}^{+}$-implanted samples. Moreover, $\mathrm{N}^{+}$-implanted samples also show the similar results. The RSM image of $\mathrm{N}^{+}$implanted $4 \mathrm{H}-\mathrm{SiC}$ with $5 \times 10^{19}$ atoms $/ \mathrm{cm}^{3}$ is shown in Fig. 4(c). Note that all the implanted samples with a relatively low concentration of $1 \times 10^{19}$ atoms $/ \mathrm{cm}^{3}$, did not cause detectable peak splitting in (0008) RSM images. From
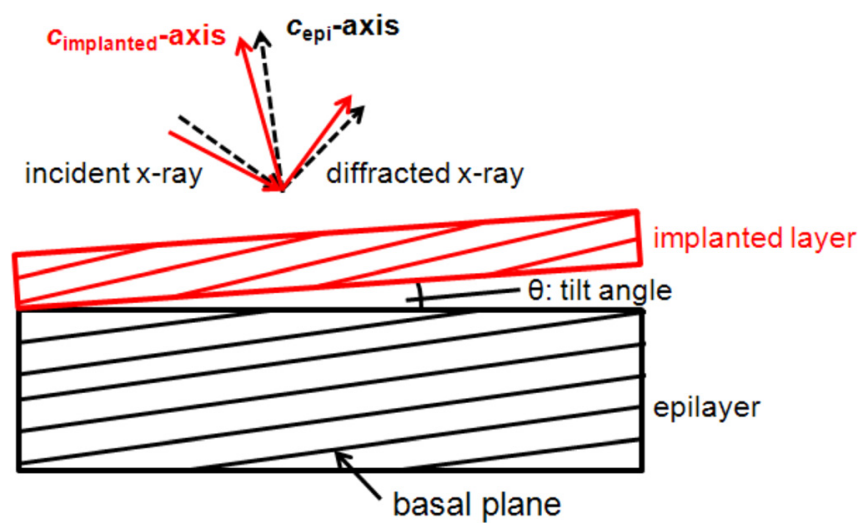

FIG. 3. Schematic drawing of the tilt direction observed after high-dose ion implantation and annealing.

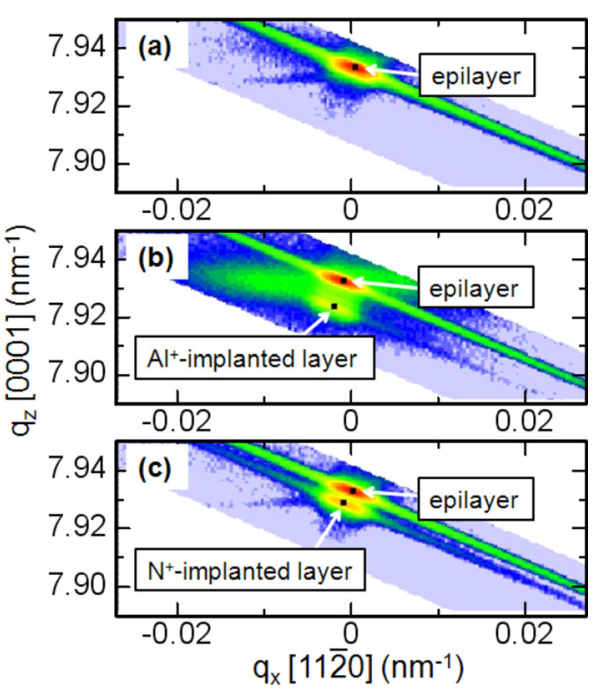

FIG. 4. (0008) RSM images of (a) and (b) $\mathrm{Al}^{+}$-implanted and (c) $\mathrm{N}^{+}$implanted $4 \mathrm{H}-\mathrm{SiC}$. The concentrations of implanted ions were (a) $\mathrm{Al}^{+}: 1 \times 10^{19}$ atoms $/ \mathrm{cm}^{3}$, (b) $\mathrm{Al}^{+}: 5 \times 10^{19}$ atoms $/ \mathrm{cm}^{3}$, and (c) $\mathrm{N}^{+}: 5 \times 10^{19}$ atoms $/ \mathrm{cm}^{3}$, respectively. The samples were annealed at $1800^{\circ} \mathrm{C}$ for $10 \mathrm{~min}$.

these results, it is confirmed that the $c$-lattice expansion and $c$-axis tilt are caused by high-dose ion implantation, irrespective of ion species, and that the tilt direction is identical for all the implanted $4 \mathrm{H}-\mathrm{SiC}$. In addition, a similar result was observed on the RSM image of the $\left(\mathrm{C}^{+}+\mathrm{Si}^{+}\right)$co-implanted sample. Since $\left(\mathrm{C}^{+}+\mathrm{Si}^{+}\right)$co-implantation also causes the $c$-lattice expansion and $c$-axis tilt, implantation-induced damage, especially extended defects, should contribute to the lattice parameter change. The detail is discussed in Sec. III B.

\section{B. Discussion}

Fig. 5 depicts the $c$-lattice mismatch between the implanted layers and the epilayers, obtained from the (0008) RSM measurements on ion-implanted $4 \mathrm{H}-\mathrm{SiC}$, as a function of the implanted ion concentration. In this figure, the result taken from the $\left(\mathrm{C}^{+}+\mathrm{Si}^{+}\right)$co-implanted $\left(\mathrm{C}^{+}: 2.5 \times 10^{19}\right.$ atoms $/ \mathrm{cm}^{3}, \quad \mathrm{Si}^{+}: 2.5 \times 10^{19}$ atoms $\left./ \mathrm{cm}^{3}\right)$ sample is also included. Fig. 5 indicates that heavier ions tend to cause larger lattice mismatch at a given concentration of implanted atoms,

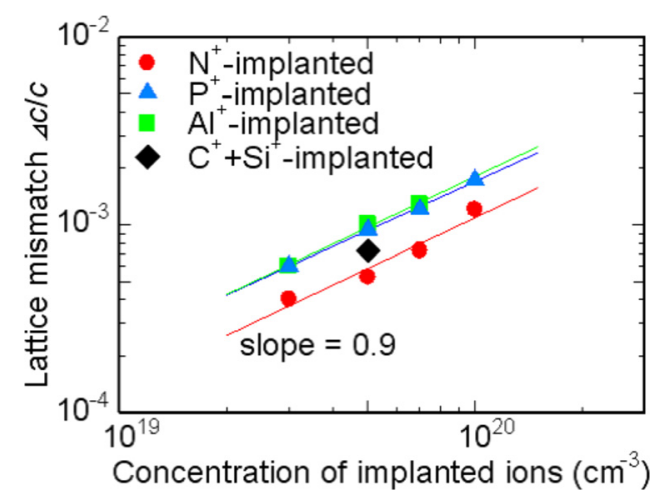

FIG. 5. Lattice mismatch between the implanted layers and the underlying epilayers observed in $\mathrm{N}^{+}-, \mathrm{P}^{+}-, \mathrm{Al}^{+}-$, and $\left(\mathrm{C}^{+}+\mathrm{Si}^{+}\right)$-implanted $4 \mathrm{H}-\mathrm{SiC}$ as a function of the implanted ion concentration. 
and the slope of the plot is close to unity. Since heavier ions generate higher amount of interstitial atoms (and vacancies) in the crystals, it is likely that interstitial atoms generated by ion bombardment play an important role. Several authors have reported lattice parameter change of $4 \mathrm{H}-\mathrm{SiC}$ crystals induced by substitutional nitrogen or aluminum atoms. ${ }^{20-23}$ Their results indicate that lattice mismatch between undoped and $\mathrm{N}$-doped $\left(\sim 4 \times 10^{19} \mathrm{~cm}^{-3}\right)$ layers is very small, in the order of $10^{-5}$, and lattice mismatch between undoped and Aldoped $\left(\sim 4 \times 10^{-20} \mathrm{~cm}^{-3}\right)$ layers is also small, in the order of $10^{-4}$. It should be noted that the $c$-lattice mismatch observed in ion-implanted $4 \mathrm{H}-\mathrm{SiC}\left(4.0 \times 10^{-4} \sim 1.7 \times 10^{-3}\right)$ is much larger than the lattice mismatch induced by substitutional dopant atoms. In Fig. 6, the $c$-lattice mismatch is plotted as a function of interstitial $\left(I_{\mathrm{C}}+I_{\mathrm{Si}}\right)$ concentration calculated by SRIM simulation. Threshold energy for atomic displacement of $22 \mathrm{eV}$ was assumed. This calculation did neither include annealing effect during the hot-implantation nor include the effect of damage accumulation. Since high-dose ion implantation was performed at $600{ }^{\circ} \mathrm{C}$ in this study, the calculated interstitial concentration is actually overestimated, e.g., the interstitial concentration should not exceed the atomic density in $\mathrm{SiC}\left(1 \times 10^{23} \mathrm{~cm}^{-3}\right)$. As seen from Fig. 6, the $c$-lattice mismatch approximately follows a straight line, irrespective of implanted ion species, which supports the above assumption that interstitials may be responsible for the lattice mismatch. The lattice mismatch observed in $\mathrm{N}^{+}$-implanted samples slightly deviates from the straight line in the figure, especially when the implant dose is very high. One possibility is that precipitation of nitrogen atoms might contribute to the lattice expansion, since the solubility limit of nitrogen atoms in $\mathrm{SiC}$ is lower than that of phosphorous and aluminum atoms. ${ }^{18,32-34}$

It has been reported that excess interstitials generated by ion bombardment create secondary defects after hightemperature annealing. ${ }^{7-9}$ TEM images were taken on ionimplanted samples. The thickness of TEM specimens was about $0.2 \mu \mathrm{m}$, and the TEM observation was operated at an energy of $300 \mathrm{keV}$. Fig. 7 shows the plan-view TEM image taken with the $\langle 0001\rangle$ zone axis for the $\mathrm{P}^{+}$-implanted sample with $1 \times 10^{20}$ atoms $/ \mathrm{cm}^{3}$. Dark contrasts were observed in the implanted and annealed sample. It is difficult to identify

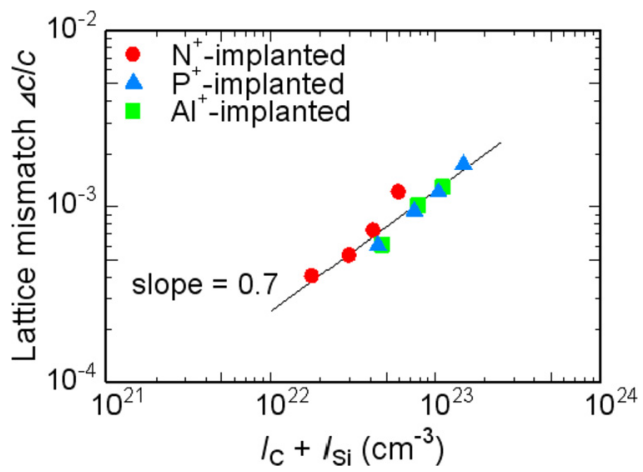

FIG. 6. Lattice mismatch between the implanted layers and the underlying epilayers as a function of interstitial $(\mathrm{C}+\mathrm{Si})$ concentration for $\mathrm{N}^{+}-, \mathrm{P}^{+}-$, and $\mathrm{Al}^{+}$- implanted $4 \mathrm{H}-\mathrm{SiC}$. The interstitial concentration was calculated by SRIM simulation.

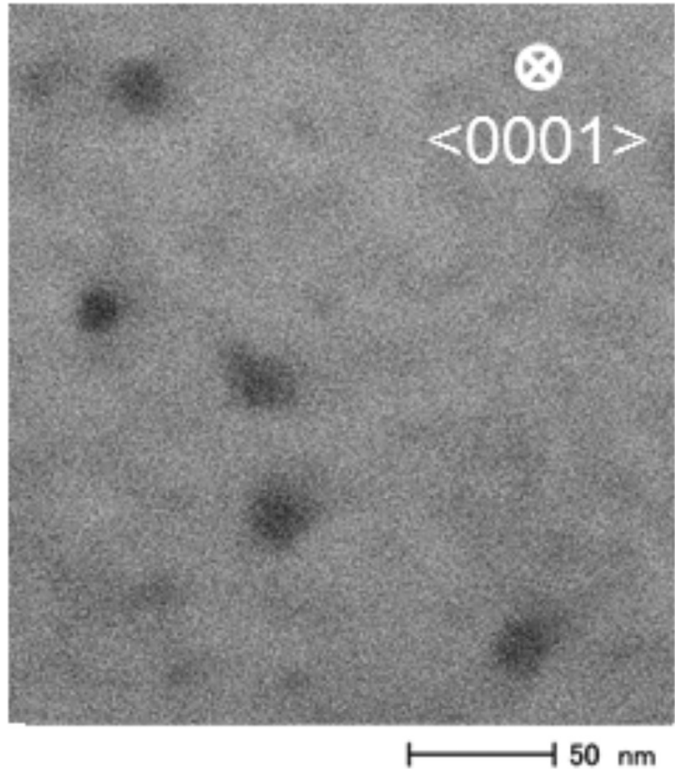

FIG. 7. Plan-view TEM image of $\mathrm{P}^{+}$-implanted $4 \mathrm{H}-\mathrm{SiC}$ taken from the $\langle 0001\rangle$ zone axis. The sample was $\mathrm{P}^{+}$-implanted with $1 \times 10^{20}$ atoms $/ \mathrm{cm}^{3}$ and annealed at $1800^{\circ} \mathrm{C}$ for $10 \mathrm{~min}$.

the exact structure of these dark contrasts only from this TEM image. Ohno and Kobayashi reported high-resolution TEM images of ion-implanted and annealed $4 \mathrm{H}-\mathrm{SiC}{ }^{7}$ They showed that $\mathrm{Si}-\mathrm{C}$ bilayers parallel to the (0001) basal planes are inserted after ion-implantation and high-temperature annealing. During annealing, platelet defects on the same basal plane move towards each other until they coalesce into one. ${ }^{9}$ Taking account of the previous reports, similar defects may be created in the present samples. The lattice mismatch observed in this study might be caused by the extra planes created after high-dose ion implantation and annealing.

The generation of extra planes may also be responsible for the $c$-axis tilt when the implanted samples have off-axis. Fig. 8 shows the cross-sectional TEM image taken with the $[11 \overline{2} 0]$ zone axis for the $\mathrm{P}^{+}$-implanted sample with $1 \times 10^{20}$ atoms $/ \mathrm{cm}^{3}$. It can be confirmed that the (0001) basal planes are locally distorted by the extra planes. In the high-dose ion-implanted $4 \mathrm{H}-\mathrm{SiC}$, the crystallographic tilt

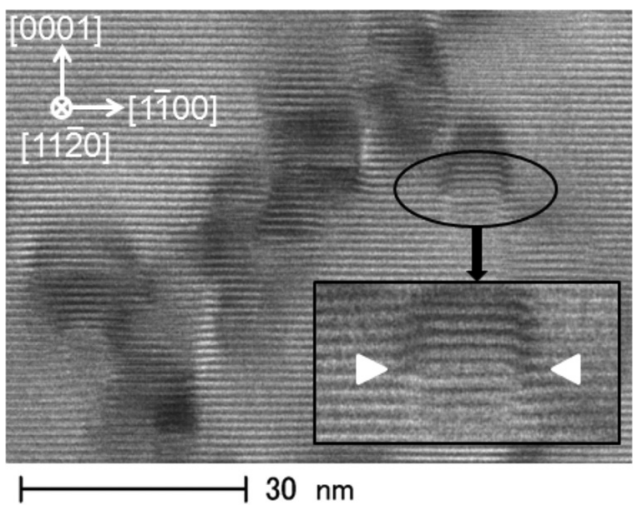

FIG. 8. Cross-sectional TEM image of $\mathrm{P}^{+}$-implanted $4 \mathrm{H}-\mathrm{SiC}$ taken from the $[11 \overline{2} 0]$ zone axis. The inset shows the magnified image of the encircled region. The sample was $\mathrm{P}^{+}$-implanted with $1 \times 10^{20}$ atoms $/ \mathrm{cm}^{3}$ and annealed at $1800^{\circ} \mathrm{C}$ for $10 \mathrm{~min}$. 


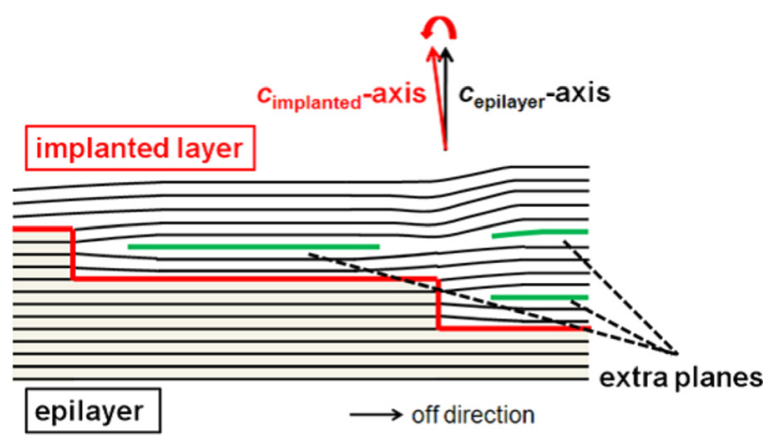

FIG. 9. Schematic illustration of the crystallographic tilt caused by extra planes (extrinsic stacking faults) on the basal planes of $4 \mathrm{H}-\mathrm{SiC}$.

may be introduced to accommodate the vertical lattice mismatch, as schematically shown in Fig. 9. The tilt direction observed in this study is consistent with the model shown in the figure. Fig. 10 shows the relation between the $c$-lattice mismatch and the tilt angle. In heteroepitaxial growth of other semiconductors, crystallographic tilt between different materials is generally explained by the Nagai's model. ${ }^{35} \mathrm{In}$ the Nagai's model, the tilt angle is given by the formula: $\tan \alpha=(\Delta d / d) \tan \phi$, where $\alpha, \Delta d / d$, and $\phi$ are the tilt angle, vertical lattice mismatch, and off-cut angle, respectively. In Fig. 10, a result calculated from the Nagai's model taking account of an $8^{\circ}$ off-cut is included as a solid line. As can be seen from the figure, the tilt angle increases as the $c$-lattice mismatch increases. However, the experimental values of the tilt angle do not follow the calculated results. Dopinginduced misorientation in off-cut $4 \mathrm{H}-\mathrm{SiC}$ has been reported from several groups. Huang et al. observed $c$-axis tilt between $\mathrm{N}$-doped epilayers and heavily doped p-type substrates ${ }^{21}$ and Huh et al. observed the tilt between Al-doped epilayers and semi-insulating substrates. ${ }^{22}$ In these reports, it was suggested that the $c$-axis tilt can be explained by the Nagai's model. However, the crystallographic tilt observed in this study is introduced not by pure lattice mismatch but by extra planes, which locally distort the crystal lattice. Therefore, the situation is somewhat different from heteroepitaxial growth systems.

The authors also investigated the implantation-induced misorientation for $4^{\circ}$ off-cut samples. Aluminum ions were implanted into $7 \mu \mathrm{m}$-thick lightly doped n-type epilayers

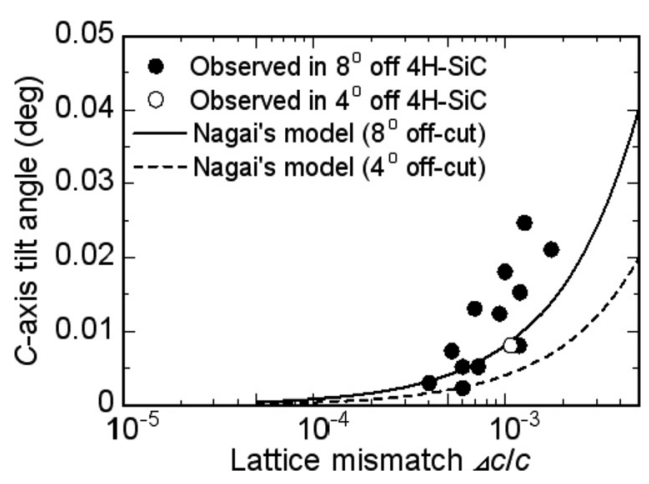

FIG. 10. Dependence of the $c$-axis tilt angle of ion-implanted layers on the lattice mismatch. The solid and dashed lines show the tilt angle calculated from the Nagai's model assuming $8^{\circ}$ off-cut and $4^{\circ}$ off-cut, respectively. with an implanted atom concentration of $1 \times 10^{19}$ $-1 \times 10^{20}$ atoms $/ \mathrm{cm}^{3}$. After the implantation, activation annealing was performed under the same condition as performed for the $8^{\circ}$ off-cut samples. In this case, incident x-ray can reach the heavily doped substrate. The RSM image of a not-implanted sample does not show detectable peak splitting. In the RSM images of implanted $4^{\circ}$ off-cut samples, the same trend was observed as observed in the $8^{\circ}$ off-cut case. For the $\mathrm{Al}^{+}$-implanted $4^{\circ}$ off-cut sample with $5 \times 10^{19}$ atoms $/ \mathrm{cm}^{3}$, the $c$-lattice mismatch was estimated as about $1.1 \times 10^{-3}$, and the tilt angle as about $0.008^{\circ}$, while the $c$-lattice mismatch and tilt angle are about $1.0 \times 10^{-3}$ and about $0.018^{\circ}$ in the $\mathrm{Al}^{+}$-implanted $8^{\circ}$ off-cut sample with $5 \times 10^{19}$ atoms $/ \mathrm{cm}^{3}$. The different off-cut angle does not affect the value of $c$-lattice mismatch very much. However, the tilt angle is clearly smaller in the case of lower offcut angle samples. This result also suggests that the $c$-axis tilt depends on the off-cut angle of the substrate in addition to the vertical lattice mismatch (smaller $c$-axis tilt on lower off-cut angle). However, the tilt angle is also higher than the value predicted by the Nagai's model assuming $4^{\circ}$ off-cut substrates as shown in Fig. 10. Therefore, the crystallographic tilt observed in this study cannot be explained with the Nagai's model, as described in the last paragraph.

\section{CONCLUSION}

$\mathrm{N}^{+}, \mathrm{P}^{+}, \mathrm{Al}^{+}$, or $\left(\mathrm{C}^{+}+\mathrm{Si}^{+}\right)$-implanted $4 \mathrm{H}-\mathrm{SiC}$ epilayers were characterized with RSM measurements in XRD. The (0008) RSM images revealed that the $c$-lattice expansion and $c$-axis tilt are introduced by high-dose ion-implantation and subsequent annealing, irrespective of ion species. The observed $c$-lattice mismatch between the implanted layers and the epilayers is in the range from $4.0 \times 10^{-4}$ to $1.7 \times 10^{-3}$. The $c$-lattice mismatch is almost in proportion to the interstitial concentration generated by the ion bombardment. The authors conclude that extra planes formed after the implantation and activation-annealing process may be responsible for the $c$-lattice expansion. The $c$-axis tilt may be caused by the vertical lattice expansion, which is induced by extra planes, and the off-cut substrates.

\section{ACKNOWLEDGMENTS}

This work was supported by the Funding Program for World-Leading Innovative R\&D on Science and Technology (FIRST Program) and a Grant-in-Aid for Scientific Research (21226008) from the Japan Society for the Promotion of Science.

${ }^{1}$ R. F. Davis, G. Kelner, M. Shur, J. W. Palmour, and J. A. Edmond, Proc. IEEE 79, 677 (1991).

${ }^{2}$ H. Matsunami and T. Kimoto, Mater. Sci. Eng. R. 20, 125 (1997).

${ }^{3}$ T. Kimoto, N. Inoue, and H. Matsunami, Phys. Status Solidi A 162, 263 (1997).

${ }^{4}$ T. Troffer, M. Schadt, T. Frank, H. Itoh, G. Pensl, J. Heindl, H. P. Strunk, and M. Maier, Phys. Status Solidi A 162, 277 (1997).

${ }^{5}$ T. Dalibor, G. Pensl, H. Matsunami, T. Kimoto, W. J. Choyke, A. Schöner, and N. Nordell, Phys. Status Solidi A 162, 199 (1997).

${ }^{6}$ K. Kawahara, G. Alfieri, and T. Kimoto, J. Appl. Phys. 106, 013719 (2009).

${ }^{7}$ T. Ohno and N. Kobayashi, J. Appl. Phys. 89, 933 (2001). 
${ }^{8}$ P. O. Å. Persson, L. Hultman, M. S. Janson, A. Hallén, R. Yakimova, D. Panknin, and W. Skorupa, J. Appl. Phys. 92, 2501 (2002).

${ }^{9}$ P. O. Å. Persson, L. Hultman, M. S. Janson, and A. Hallén, J. Appl. Phys. 100, 053521 (2006).

${ }^{10}$ R. Nipoti, E. Albertazzi, M. Bianconi, R. Lotti, G. Lulli, M. Cervera, and A. Carnera, Appl. Phys. Lett. 70, 3425 (1997).

${ }^{11}$ M. Ishimaru, R. M. Dickerson, and K. E. Sickafus, Appl. Phys. Lett. 75, 352 (1999).

${ }^{12}$ E. Oliviero, C. Tromas, F. Pailloux, A. Declémy, M. F. Beaufort, and C. Blanchard, Mater. Sci. Eng., B 102, 289 (2003).

${ }^{13}$ J. F. Barbot, S. Leclerc, M. L. David, E. Oliviero, R. Montsouka, F. Pailloux, D. Eyidi, M. F. Denanot, M. F. Beaufort, A. Declémy, V. Audurier, and C. Tromas, Phys. Status Solidi A 206, 1916 (2009).

${ }^{14}$ D. Åberg, A. Hallén, P. Pellegrino, and B. G. Svensson, Appl. Phys. Lett. 78, 2908 (2001).

${ }^{15}$ S. Mitra, M. V. Rao, N. Papanicolaou, K. A. Jones, M. Derenge, O. W. Holland, R. D. Vispute, and S. R. Wilson, J. Appl. Phys. 95, 69 (2004).

${ }^{16}$ F. Schmid, M. Laube, G. Pensl, G. Wagner, and M. Maier, J. Appl. Phys. 91, 9182 (2002).

${ }^{17}$ Y. Negoro, K. Katsumoto, T. Kimoto, and H. Matsunami, J. Appl. Phys. 96, 224 (2004).

${ }^{18}$ Y. Negoro, T. Kimoto, H. Matsunami, F. Schmid, and G. Pensl, J. Appl. Phys. 96, 4916 (2004)

${ }^{19}$ H. Jacobson, J. Birch, C. Hallin, A. Henry, R. Yakimova, T. Tuomi, E. Janzén, and U. Lindefelt, Appl. Phys. Lett. 82, 3689 (2003).

${ }^{20}$ H. J. Chung and M. Skowronski, J. Cryst. Growth 259, 52 (2003).

${ }^{21}$ X. Huang, M. Dudley, and R. S. Okojie, Mater. Res. Soc. Symp. Proc. 815, 121 (2004)
${ }^{22}$ S. W. Huh, H. J. Chung, M. Benamara, M. Skowronski, J. J. Sumakeris, and M. J. Paisley, J. Appl. Phys. 96, 4637 (2004).

${ }^{23}$ S. Sasaki, J. Suda, and T. Kimoto, in Proceedings of ICSCRM2011 (2012).

${ }^{24}$ X. Zhang, M. Skowronski, K. X. Liu, R. E. Stahlbush, J. J. Sumakeris, M. J. Paisley, and M. J. OfLoughlin, J. Appl. Phys. 102, 093520 (2007).

${ }^{25}$ M. Nagano, H. Tsuchida, T. Suzuki, T. Hatakeyama, J. Senzaki, and K. Fukuda, J. Appl. Phys. 108, 013511 (2010).

${ }^{26}$ X. Zhang, M. Nagano, and H. Tsuchida, Mater. Sci. Forum 679-680, 306 (2011).

${ }^{27}$ J. P. Bergman, H. Lendenmann, P. Å. Nilsson, U. Lindefelt, and P. Skytt, Mater. Sci. Forum 353-356, 299 (2001).

${ }^{28}$ M. Skowronski and S. Ha, J. Appl. Phys. 99, 011101 (2006).

${ }^{29}$ J. F. Ziegler, J. P. Biersack, and U. Littmark, The Stopping and Range of Ions in Solids (Pergamon, New York, 1985).

${ }^{30}$ J. F. Ziegler, M. D. Ziegler, and J. P. Biersack, sRIM, 2008, software package, http://www.srim.org.

${ }^{31}$ H. J. von Bardeleben, J. L. Cantin, L. Henry, and M. F. Barthe, Phys. Rev. B 62, 10841 (2000).

${ }^{32}$ M. Laube, F. Schmid, G. Pensl, G. Wagner, M. Linnarsson, and M. Maier, J. Appl. Phys. 92, 549 (2002).

${ }^{33}$ M. Bockstedte, A. Mattausch, and O. Pankratov, Appl. Phys. Lett. 85, 58 (2004).

${ }^{34}$ M. K. Linnarsson, M. S. Janson, U. Zimmermann, B. G. Svensson, P. O. Å. Persson, L. Hultman, J. Wong-Leung, S. Karlsson, A. Schöner, H. Bleichner, and E. Olsson, Appl. Phys. Lett. 79, 2016 (2001).

${ }^{35}$ H. Nagai, J. Appl. Phys. 45, 3789 (1974). 